\title{
How Will We Breathe Tomorrow?
}

\author{
Jessica Broscheit \\ Hamburg University of \\ Applied Sciences \\ Berliner Tor 7 \\ 20099 Hamburg, Germany \\ jessica.broscheit@haw-hamburg.de
}

\author{
Susanne Draheim \\ Hamburg University of \\ Applied Sciences \\ Berliner Tor 7 \\ 20099 Hamburg, Germay \\ susanne.draheim@haw-hamburg.de
}

\author{
Kai von Luck \\ Hamburg University of \\ Applied Sciences \\ Berliner Tor 7 \\ 20099 Hamburg, Germany \\ luck@informatik.haw-hamburg.de
}

\begin{abstract}
This paper presents the concept of a fiction-driven workshop that was conducted using a process called D/A/R/E. The aim of this design-orientated approach is to address environmental issues with citizens and empower them in understanding digital technology concepts. Within the framework of an urban artist research and mediation project, a pilot study on the question 'How will we breathe tomorrow?' was devised. For this endeavour, participants were introduced to the subject of air quality and took part in the process of creating a personal data-based future artefact with sensor technology. In the spirit of Antony Dunne and Fiona Raby, these functional artefacts were used as tools to better comprehend the present and discuss a desirable future. Additionally, they were utilised to engage the broader public in environmental, digital, and ethical issues.
\end{abstract}

Fiction-driven Design Research. Perceptions of Air Quality. Citizen Participation

\section{INTRODUCTION}

The Earth's atmosphere consists of an essential element-air-which creates a seamless matrix that interlinks everything (Suzuki et al., 2007). This matrix of gases, particles, and liquids, is in a continuous state of change. It further depends on dynamic atmospheric processes which all influence the air quality (Lahl and Steven, 2005). One air pollutants exposure is particulate matter (PM). Particulate matter is a complex mixture of solid and liquid concentrations, measured in mass per volume of air $\left(\mu \mathrm{m} / \mathrm{m}^{3}\right)$. These particles are categorized according to their aerodynamic diameter as follows (Brook et al., 2010; Lahl and Steven, 2005):

- $\quad \mathrm{PM}_{10}$ are particles with a diameter $<10 \mu \mathrm{m}$;

- $\quad \mathrm{PM}_{2.5}$ are particles with a diameter $<2.5 \mu \mathrm{m}$;

- UFP are ultrafine particles with a diameter $<0.1 \mu \mathrm{m}$.

These concentrations have an impact on the environment and affect human health on a global scale (Lahl and Steven, 2005; Brook et al., 2010). For instance, particulate matter $\left(\mathrm{PM}_{2.5}\right)$ and UFP are not only capable of entering the respiratory tract, but also the bloodstream, and can causes respiratory and cardiovascular health problems (Brook et al., 2010; Lahl and Steven, 2005). Furthermore, human activity has a significant influence on air quality. That let amongst other environmental impacts, to global ecological change, which is referred to as
'Anthropocene' (Crutzen, 2006). According to Paul Crutzen (2006), the Anthropocene era poses an enormous challenge of balancing human activities with the ecological resilience of habitats. To face this challenge, new solutions of sustainability must be found, including digital technologies such as ubiquitous computing. Ubiquitous computing envisions communication systems in which many low-power computers are both interconnected within a network and usable by many users (Weiser, 1999). Nowadays, this digital technology is utilised for a myriad of use cases, such as sensor networks which receive data and run user interfaces that interact with human beings in their everyday lives (Mattern and Flörkemeier, 2010). With these sensor network information systems, the atmosphere can be measured ubiquitously to leverage strategies that facilitate a more resource-efficient environment (Mattern and Flörkemeier, 2010; Gabrys, 2015). A strategy that might offer effective solutions for the urban environment is that of 'Smart City'. In this concept, 'intelligent' cities are transformed by databased processes for networking supply systems-so that, for example, particulate matter exposures ( $P M_{10-2.5}$ can be regulated by controlling the volume of road traffic (Gabrys, 2015). However, the concept of a Smart City entails serious ethical challenges due to use of digital technologies such as security and data policy (Mattern and Flörkemeier, 2010; Gabrys, 2015). Because of the rapid changes in environmental and technology-related challenges, an interdisciplinary approach of knowledge- 
gathering is required. In this light, a participation of people with a diverse set of skills is asked for, to offer multifarious solutions to these complex demands. But how can citizens be empowered to respond to environmental and digital challenges?

To address this issue, it sought after an alternative knowledge transfer medium. Artists are often attributed by the ability to address key issues through their aesthetics (Hildebrandt, 2012). Particularly, public art offers a promising way to reflect on new forms of action. Thus, it empowers citizens to engage with key issues through the participation in an artistic practice. At the same time, the artist is dependent on cooperation, to turn a brief impulse into a sustainable space for action (Hildebrandt, 2012). Within the scope of the urban artist research and mediation project called the A/D/A festival, the workshop 'How will we breathe tomorrow?' subsequently resulted in a pilot study. The aim of the workshop was to support participants in the development of a functional and data-based future artefact, designed to visualize hazardous levels of particulate matter $\left(\mathrm{PM}_{2.5}\right)$. To provide a framework for and to easily communicate environmental and digital technology issues to the lay person, a process called 'D/A/R/E' was created (Broscheit, 2017). Its rationale is to leverage fictiondriven design approaches and open hard- and software tools. This paper describes the D/A/R/E process and the pilot study addressing the aforesaid question 'How will we breathe tomorrow?'.

\section{D/A/R/E}

The $D / A / R / E$ process was initiated to conduct design-orientated approaches to address key issues and to empower participants to understand digital technology concepts. The acronym D/A/R/E represents the different stages of the workflow, and stands for DREAM, ANALYSIS, REALITY, as well as EXCHANGE. Primarily, D/A/R/E aims at helping organizers to structure the workshops and providing participants with an overview of the different stages. In addition, D/A/R/E is intended to express an attitude of creative, interdisciplinary, and goaloriented working with digital technology on key issues. Moreover, $D / A / R / E$ is flexible in its applicability to different researches and is not limited to any specific questions or time schedules. Alongside environmental issues, D/A/R/E further contributes toward conveying technical concepts and inviting discussions on ethical concerns. To initiate discussions of the question 'How will we breathe tomorrow?', this paper presents the process of $D / A / R / E$ to shed light on the environmental issue of particulate matter.

\subsection{Dream}

Considering to the rapid change of environmental spheres and digital technologies, D/A/R/E sets a focus on the near future, to provide a space for action and flexible thinking. For this reason, the phase 'DREAM' is based on Science Fiction writing tools and fiction-driven design methods, such as 'Diagetic Prototype' (Kirby, 2010), 'Design Fiction' (Bleeker, 2009; Sterling, 2009), and 'Speculative Design' (Dunne and Raby, 2014). These methods are mainly used by designers and artists to visualize a near future, but it is not necessary that the speculative idea has to work technically. Contrary to this approach, the process D/A/R/E enables participants to implement a speculative and functional idea. Furthermore, it allows them to understand contents and technology in the process of actual creation.

In the 'DREAM' phase, a thesis provides a framework for considering key issues. As in the Science Fiction tradition, a simplified what-ifquestion is used as a tool to suggest a speculative scenario, and provide scientific and technological knowledge (Rey, 1979; Dunne and Raby, 2014; Schäfer, 2014). With this approach, participants are confronted with a key issue in an imaginative way and are introduced to a future scenario that can then be explored.

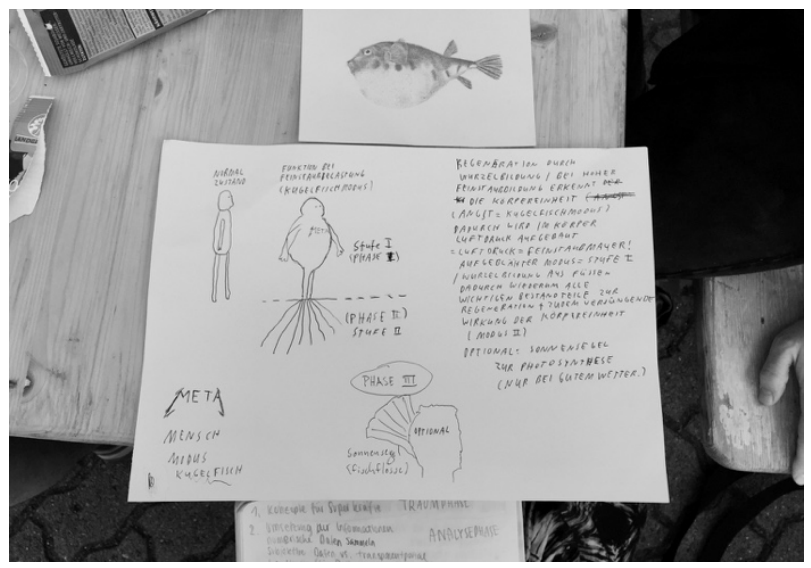

Figure 1: The participants sketched an idea based on the pufferfish. Image: Saskia Kraft

\subsection{Analysis}

The phase 'ANALYSIS' is about exploring the information associated with the subject. Thus, participants are provided with basic information about the key issue and relevant scientific and technological knowledge. They are invited to explore their perception and those of other lifeforms, in order to study the workshop issue. Particularly, the workshop 'How will we breathe tomorrow?' must convey the following information. First, participants have to get informed about open data measurements, such as Hamburg's official airmonitoring stations (Reich et al., 2016). Second, participants have to be educated regarding the concepts of ubiquitous computing, sensor networks, and data collection (Weiser, 1999; Mattern and Flörkemeier, 2010). Third, participants have to be 
instructed to create their ideas as tangible user interfaces (Ishii, 2008; Ishii et al., 2012). In addition to the general information, the creative process is enhanced by the analysis of the participants individual perceptions. Therefore, participants require knowledge relating to the sensorimotor capabilities of different species, to explore other perceptions of reality (von Uexküll, 1921; von Uexküll and Kriszat, 1934; Penny, 2017, p. 17) (Figure 1).

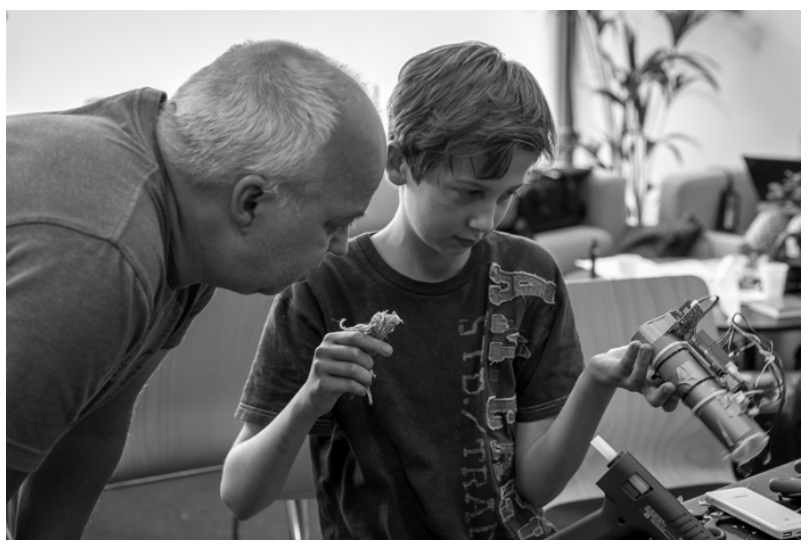

Figure 2: The participants prototype their artefact of the future. Image: André Jeworutzki.

\subsection{Reality}

The phase 'REALITY' addressing the realising process of an idea and is based on rapid prototyping and open hard- and software tools (Figures 2 and 3 ). The aim of REALITY is to create a tangible user interface (TUI) to extend the physical world with digital information (Ishii, 2008; Ishii et al., 2012). To this end, a construction kit is provided to enable participants to build their own tangible interface with open soft- and hardware tools (Buechley et al., 2008). In the context of the workshop 'How will we breathe tomorrow?', the construction kit included a microcontroller Arduino, the optical particle sensor PPD42NS, a chainable RGB-LED, and a piezo buzzer. The sensor PPD42NS detects the optical density of the air and the microcontroller transforms the information into light and sound. These components are designed to enable the participants to perceive particulate matter $\left(\mathrm{PM}_{2.5}\right)$ in real time and to allow them to create a 'personal digital data assemblage' in which they can individually monitor the environment in their everyday lives (Lupton, 2017).

\subsection{Exchange}

The phase 'EXCHANGE' is concerned with the presentation of the futuristic data-based artefacts to the general public. (e.g., art gallery and on social media networks). Similar to Anthony Dunne and Fiona Raby (2014), who coined the term 'Speculative Design', the D/A/R/E process utilises functional artefacts as tools to better understand the present and to envision future perspectives. To this end, the usual modes of communication such as exhibitions, publications, press, and the Internet, are used to convey future images to the general public (Bleeker, 2009; Dunne and Raby, 2014; Kirby, 2010).

\section{PILOT STUDY}

Following a public announcement on the $A / D / A$ festival website, eight participants (aged 12-47) finally signed up for the two-day pilot study. It is noted that programming skills were not mandatory to participate in the workshop.

The first day of the workshop set out with an introduction to the D/A/R/E process, and the phases 'DREAM' and 'ANALYSIS'. The introduction covered personal motivation, facts, access to public data, and an excursion to Hamburg's official airmeasuring station. To stimulate ideas on breathing and air quality in the future, participants were presented with a dystopian scenario and the question: 'What if humans could extend their senses and perceive the values of particulate matter $\left(\mathrm{PM}_{2.5}\right)$ in real time?'

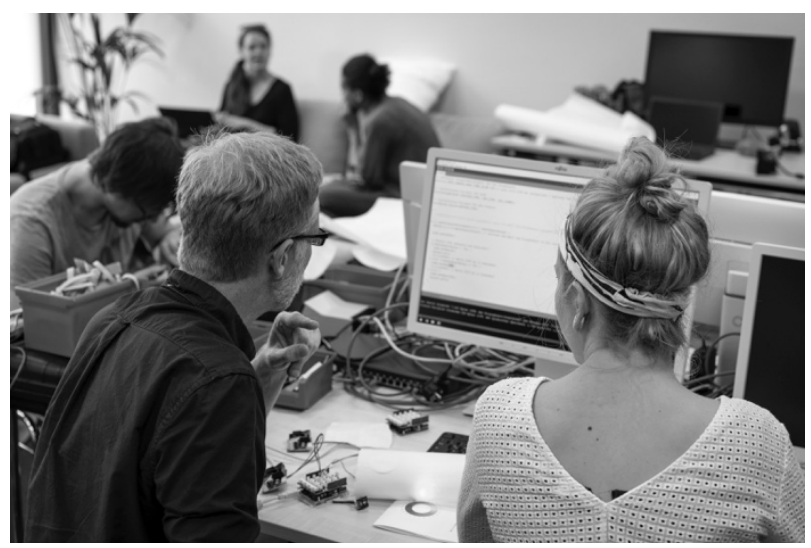

Figure 3: Participants programming the microcontroller. Image: André Jeworutzki.

To assist participants in engaging in the creative process, the metaphor of a superhero was used, to visualise different skills and possibilities of perception. In addition, the creativity of the participants was fostered by confronting them to printed postcards illustrating various species. The participants could choose one of their favourite species and analyse their different sensorimotor capabilities. Additionally, they received a booklet in which to record their individual perceptions of the environment and to facilitate creation of their personal data-based future artefact. The first day closed with presentations of both the different ideas and personal experiences on environmental issues (Figure 1). 
The second day started with the phase 'REALITY'. First, participants received a construction kit and an introduction to the Arduino IDE, to implement their idea as functional prototype (Figures 2 and 3 ). The code was simplified and included comments to explain the different functions of the code snippets. The interface for both the sensor and actuators had already been pre-developed, enabling participants to concentrate on the interaction with the prototype by modifying the code. To trigger the interaction of the tangible interfaces, vapour was blown onto them. At the end of the second day, the participants implemented their ideas with the electronic components and various materials such as cardboard, paper, and hot glue. To 'EXCHANGE' and discuss the results in public, the data-based future artefacts were presented at the A/D/A festival for the duration of one week. In addition, images of these artefacts were disseminated on websites and popular social media channels.

\subsection{Results}

In this pilot study, participants based their ideas on different species and proved that they understood the environmental issue and technological concept by creating a functional artefact. For example, they used the mouse, the chameleon, the pufferfish, and the skunk as sources of inspiration, and implemented the following ideas. There follows a description of the varying prototypes.

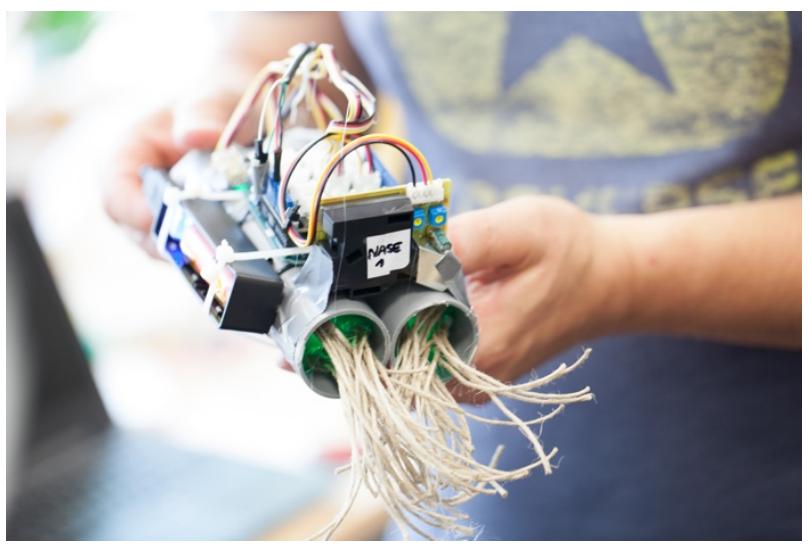

Figure 4: Prototype based on the whiskers of a mouse. Image: Jessica Broscheit.

\subsubsection{Nose 1}

Inspired by the sensitive whiskers of a mouse, the participants created a prototype called 'Nose 1' (Figure 4). This illustrates the idea of intelligent hairs in the human nose, which can detect the critical value of particulate matter to regulate the openings of the respiratory system. Depending on these values, the nostrils light up in a Green or Red colour. Thus, others are provided with an immediate feedback of their surrounding environment. In addition to the construction kit, the participants attached an independent power supply, to let the nose to 'float' without wires.

\subsubsection{Reactive Skin}

Inspired by the reactive skin of the chameleon (which has the ability to change its skin colour according to environmental conditions), a paper arm with a macro view of skin cells was created (Figure 5). Typically, the skin has a unicoloured tone, but if the optical sensor detects a hazardous value, this tone turns into rainbow-colours. In doing so, people's attention is drawn to the critical state of the air.

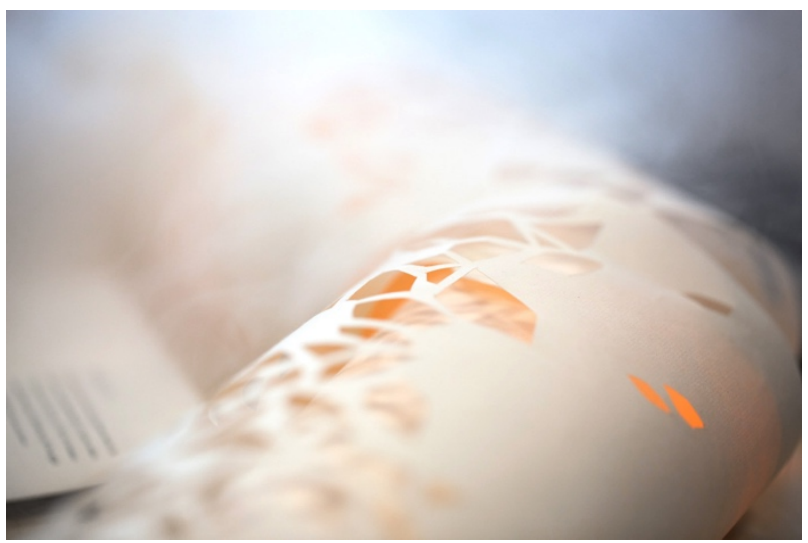

Figure 5: Prototype based on the reactive skin of a chameleon. Image: Jessica Broscheit.

\subsubsection{Pufferfish Modus}

Inspired by the sensorimotor capabilities of the pufferfish, which can inflate when in danger, an animated illustration showed two conditions of the human body that depended on air quality (Figure 6). Participants placed the speculative illustration on a cardboard display and animated it with the construction kit. If the particle sensor detects a hazardous value, the body 'inflates' and aspirates the remaining healthy air. Then the feet start to root down, like a tree, and draw energy from the soil.

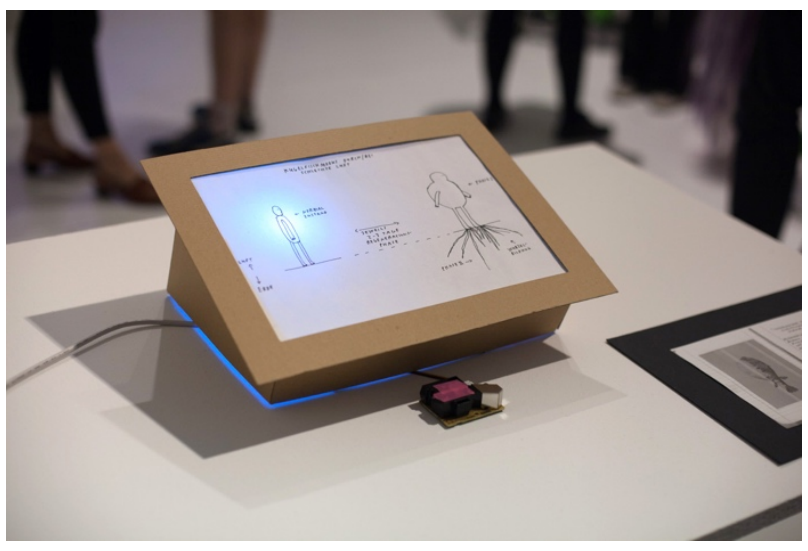

Figure 6: Animated illustration based on a pufferfish. Image: Jessica Broscheit. 


\subsubsection{Le Fleur}

Inspired by the behaviour of a skunk, that attacks in case of danger, participants created a mutated skunk out of cardboard, paper, and the construction kit (Figure 7). This mutated skunk acts as a somehow social credit system for air quality and invites car drivers to take part in a 'particulate matter diary'. This prototype explores the environment and is aware of who is responsible for high emissions.

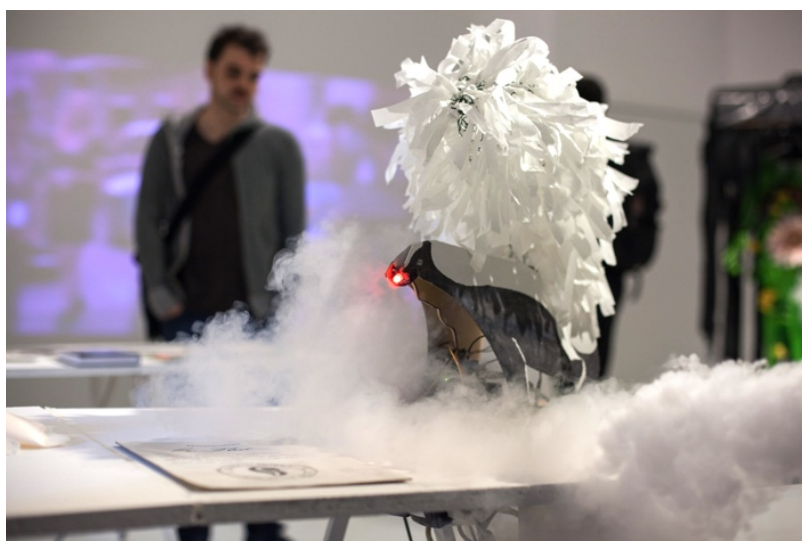

Figure 7: Mutated skunk as social credit system. Image: Jessica Broscheit.

\section{CONCLUSION}

This paper introduced a fiction-driven workshop that was conducted by using a process called D/A/R/E. This process was developed to enable participants to work on environmental and digital technology issues within a design-oriented framework. As part of an urban artist research and mediation project, this workshop focused on particulate matter $\left(\mathrm{PM}_{2.5}\right)$ and convey citizens to implement functional prototypes within a two-day period. At the end of the workshop, the results and the process itself were presented to the public at an art gallery, and on websites, as well as on social media channels.

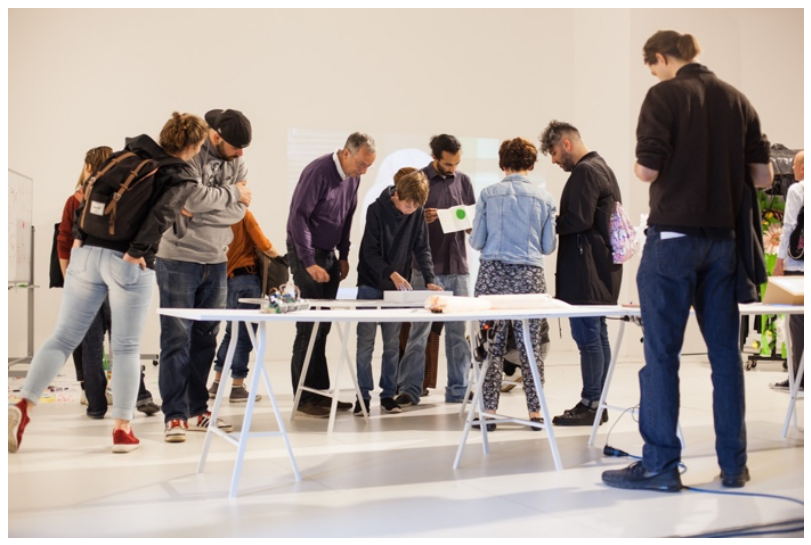

Figure 8: A/D/A festival presentation. Image: Jessica Broscheit.
To conclude, the $D / A / R / E$ process is introduced to convey issues of particulate matter, digital technology, and ethics by leveraging data-based future artefacts. As revealed in Section 3.1, participants were invited to express their response to the question 'How will we breathe tomorrow?' in the form of functional prototypes. Participants experienced no issues in modifying code and in implementing their ideas as functional artefacts. Generally, participants appreciated this fictiondriven workshop and were enthusiastic about implementing their ideas and presenting them at the art gallery. Inspired by the presentations, further dialogues were held with visitors to the exhibition (Figure 8). Furthermore, the utilised construction kit was stable and operated as expected. However, the optical particle sensor PPD42NS cannot be recommended for human-computer interaction scenarios, since fast sampling rates occur data errors. Another disadvantage is the bottom-up framework of the pilot study. To convey the workshops results to policy-makers, new structures are required. As well the workshop is participant limited. Only small groups can be supervised in an artistic framework like this. In summary, it can be concluded that the process $D / A / R / E$ and the combination of environmental issues, digital technology, presentation, and discussion offers a promising mode of knowledge transfer.

\section{FUTURE WORK}

The present pilot study focused on the implementation of the workshop method. Further work is required to prove and evaluate the process of $\mathrm{D} / \mathrm{A} / \mathrm{R} / \mathrm{E}$ and the question 'How will we breathe tomorrow?'. Promising future research directions stem from, for instance, the application of the discussed method in international contexts to incorporate different point of views and requirements-thereby including a diverse set of people from science, art, and urban development.

\section{ACKNOWLEDGEMENTS}

We would like to thank the A/D/A festival, Fab Lab St. Pauli, and the Creative Space for Technical Innovations at Hamburg University of Applied Sciences, for supporting this project.

http://ada-hamburg.de

http://fablab-hamburg.org

http://csti.haw-hamburg.de

\section{REFERENCES}

Bleeker, J., 2009. Design Fiction. A short essay on design, science, fact and fiction. [WWW Document]. URL http://bit.ly/1sm4hdR (accessed 12.10.16). 
Brook, R.D., Rajagopalan, S., Pope, C.A., Brook, J.R., Bhatnagar, A., Diez-Roux, A.V., Holguin, F., Hong, Y., Luepker, R.V., Mittleman, M.A., Peters, A., Siscovick, D., Smith, S.C., Whitsel, L., Kaufman, J.D., 2010. Particulate Matter Air Pollution and Cardiovascular Disease: An Update to the Scientific Statement From the American Heart Association. Circulation 121, 2331-2378. https://doi.org/10.1161/CIR.0b013e3181dbece1

Broscheit, J., 2017. D/A/R/E - Sichtbarkeit durch datenbasierte Zukunftsbilder. Hamburg University of Applied Sciences, Hamburg.

Buechley, L., Eisenberg, M., Catchen, J., Crockett, A., 2008. The LilyPad Arduino: Using Computational Textiles to Investigate Engagement, Aesthetics, and Diversity in Computer Science Education, in: Proceedings of the SIGCHI Conference on Human Factors in Computing Systems, CHI '08. ACM, New York, NY, USA, pp. 423-432. https://doi.org/10.1145/1357054.1357123

Crutzen, P.J., 2006. The "Anthropocene," in: Earth System Science in the Anthropocene. Springer, Berlin, Heidelberg, pp. 13-18. https://doi.org/10.1007/3-540-26590-2_3

Dunne, A., Raby, F., 2014. Speculative Everything: Design, Fiction, and Social Dreaming. The MIT Press, Cambridge, Massachusetts ; London.

Gabrys, J., 2015. Programmieren von Umgebungen, in: Sprenger, F., Engemann, C. (Eds.), Internet Der Dinge. Transcript.

Hildebrandt, P.-M., 2012. Urbane Kunst, in: Eckardt, D. rer pol F. (Ed.), Handbuch Stadtsoziologie. VS Verlag für Sozialwissenschaften, pp. 721-744. https://doi.org/10.1007/978-3-531-94112-7_32

Ishii, H., 2008. Tangible Bits: Beyond Pixels, in: Proceedings of the $2 \mathrm{Nd}$ International Conference on Tangible and Embedded Interaction, TEI '08. ACM, New York, NY, USA, pp. xv-xxv. https://doi.org/10.1145/1347390.1347392

Ishii, H., Lakatos, D., Bonanni, L., Labrune, J.-B., 2012. Radical Atoms: Beyond Tangible Bits, Toward Transformable Materials. interactions 19, 38-51. https://doi.org/10.1145/2065327.2065337

Kirby, D., 2010. The Future is Now Diegetic Prototypes and the Role of Popular Films in Generating Real-world Technological Development. Soc. Stud. Sci. 40, 41-70. https://doi.org/10.1177/0306312709338325

Lahl, U., Steven, W., 2005. Feinstaub - eine gesundheitspolitische Herausforderung. Pneumologie 59, 704-714. https://doi.org/10.1055/s-2005-915558

Lupton, D., 2017. Feeling your data: Touch and making sense of personal digital data. New Media
Soc. 19 , https://doi.org/10.1177/1461444817717515

Mattern, F., Flörkemeier, C., 2010. Vom Internet der Computer zum Internet der Dinge. Inform.-Spektrum 33, 107-121. https://doi.org/10.1007/s00287-0100417-7

Penny, S., 2017. Making Sense. Mit University Press Group Ltd, Cambridge, MA.

Reich, T., Gömer, D., Matzen, 2016. Hamburger Luftmessnetz (HaLm) [WWW Document]. URL http://luft.hamburg.de/ (accessed 11.3.16).

Rey, L. del, 1979. The world of science fiction, 19261976: The history of a subculture. Ballantine Books, New York.

Schäfer, R., 2014. Design Fiction, iF Schriftenreihe. Institut Futur, Freie Universität Berlin, Berlin.

Sterling, B., 2009. COVER STORY: Design Fiction. interactions 16, 20-24. https://doi.org/10.1145/1516016.1516021

Suzuki, D., McConnell, A., Mason, A., 2007. The Sacred Balance: Rediscovering Our Place in Nature, Updated. ed. Greystone Books, Vancouver B.C.

von Uexküll, J., 1921. Umwelt und Innenwelt der Tiere. Springer Berlin Heidelberg, Berlin, Heidelberg. https://doi.org/10.1007/978-3-66224819-5

von Uexküll, J., Kriszat, G., 1934. Streifzüge durch die Umwelten von Tieren und Menschen Ein Bilderbuch unsichtbarer Welten: Einundzwanzigster Band. Springer-Verlag, Berlin.

Weiser, M., 1999. The Computer for the 21st Century. SIGMOBILE Mob Comput Commun Rev 3, 3-11. https://doi.org/10.1145/329124.329126 